\title{
PRAGMÁTICA ILOCUCIONÁRIA E SIGNIFICAÇÃO
}

Lucrécio Araújo de Sá Júnior ${ }^{1}$

Resumo: Durante o período clássico, filósofos e gramáticos desenvolveram uma teoria ideacional do significado de acordo com as sentenças que servem para realizar atos de pensamentos como julgamentos, pedidos, comandos e crenças para o propósito da comunicação. Ė de acordo com os atos ilocucionários que o falante expressa e comunica seus pensamentos na realização do discurso. Tais atos são performativos no momento da elocução, através da articulação de sentenças apropriadas num contexto adequado de enunciação.

Palavras-chave: Filosofia da Linguagem, Atos de fala, Conversação, Significado.

Abstract. During the classical age, philosophical grammarians developed an ideational theory of meaning according to which sentence utterances serve to make acts of thoughts like judgments, requests, commands and beliefs for the purpose of communication. It is in the attempted performance of illocutionary acts that speakers express and communicate their thoughts in the conduct of discourse. Such acts are performed at a moment of utterance by uttering an appropriate sentence in an adequate context of utterance.

Key words: Philosophy of language, Speech acts, Conversation, Meaning.

\section{CONSIDERAÇÕES INICIAIS...}

O sentido de um enunciado não pode ser estabelecido apenas através da análise de seus elementos sintáticos e semânticos constituintes. Ao contrário, são as condições de uso do enunciado que determinam o seu significado. A Pragmática ilocucionária ${ }^{2}$ é uma Pragmática da relação falante-ouvinte, tal como estabelece Grice (1989) nas implicaturas conversacionais, o significado não está atado a estrutura das palavras ou frases.

1 Doutorando na Universidade Federal da Paraíba - UFPB e na Faculdade de Letras da Universidade de Lisboa - UL. Endereço eletrônico: lucrecio.sa@gmail.com.

2 Charles Morris (1959) propõe um componente pragmático na teoria dos signos. Em "Foundations of the Theory of Signs", Morris propõe a tripartição da Semiótica em sintaxe, semântica e pragmática. A Pragmática investiga a dimensão da relação entre o signo e seu utilizador, já a semântica investiga a maneira como o signo denota seu objeto. O que nos parece relevante aqui é o fato de considerar-se que a dimensão pragmática é governada por um sistema de regras que são independentes das dimensões sintática e semântica e, simultaneamente, correlacionada com elas. $\mathrm{O}$ sentido de um enunciado não pode ser estabelecido apenas através da análise de seus elementos constituintes. Ao contrário, são as condições de uso do enunciado que determinam o seu significado. 
O significado, sob a ótica da Teoria dos atos de fala, indica uma crença na harmonia como uma noção central à comunicação, tanto na dimensão do código quanto na dos mecanismos inferenciais. Tal fato se verifica especificamente em Grice no "princípio da cooperação", base da implicatura conversacional. Em Searle (1969/1983), também verificamos a crença na harmonia como fundamental à comunicação, tanto na dimensão do código quanto na dos mecanismos inferenciais. Em primeiro lugar, o objetivo da comunicação é alcançar o reconhecimento das intenções de outro (o falante); em segundo lugar, os procedimentos do ouvinte (para o reconhecimento das intenções) são um espelho dos procedimentos do falante (para apresentá-las).

Analisaremos a abordagem do discurso, a partir das noções de "contexto", de "comunicação" e de "significado. Contudo, antes de estabelecermos tal análise, para justificar o recorte dos autores analisados neste artigo, é relevante apontar que nossas observações sobre as teorias de Grice e de Searle se estendem à totalidade dos estudos intitulados "pragmáticos". Sob o rótulo "pragmática" é importante ter em mente conceitos relativos a várias tradições de análise do discurso - "função", "intencionalidade", "cooperação", "polidez", "contexto", "cultura”, "estilo", "comunicação" e "intertextualidade".

\section{Pragmática Ilocucionária GriceANA}

Grice estabelece uma distinção entre dois tipos de significado, o "significado do falante (conversacional)" - de caráter pragmático - e o "significado da sentença (convencional)" - de natureza semântica. Na proposta de Grice, o primeiro está relativamente desvinculado do segundo, ou seja, o que o falante intenciona comunicar não está necessariamente relacionado ao significado convencional. O significado do falante, não estando totalmente subordinado ao código, pode ser inferido por processos diferenciados da decodificação gramatical e lexical. Neste sentido, é central o conceito de implicitação: uma inferência sobre a intenção do falante, que resulta da decodificação de significados e da aplicação de princípios conversacionais. Ou seja, as implicaturas do tipo conversacional são inferências contextuais e não marcadas discursivamente, sendo fruto da capacidade racional dos falantes. Nas palavras de Grice:

Para deduzir que uma implicatura conversacional determinada se faz presente, $o$ ouvinte operará com os seguintes dados: (1) o significado convencional das palavras usadas, juntamente com a identidade de quaisquer referentes pertinentes; (2) o princípio da cooperação e suas máximas; (3) o contexto, lingüístico ou extralingǘstico, da enunciação; (4) outros itens de seu conhecimento anterior; e (5) o fato (ou fato suposto) de que todos os itens relevantes cobertos por (1) - (4) são acessíveis a ambos os participantes e ambos sabem ou supõe que isto ocorra (GRICE, 1957, p. 93). 
Apesar do destaque dado ao contexto, conforme se verifica no trecho acima, podemos afirmar que um limite da pragmática griceana é exatamente o não tratamento desta noção ${ }^{3}$. Embora Grice se refira aos contextos "extra-lingüísticos" e ao conhecimento de mundo dos falantes (respectivamente nos itens (3) e (4) do trecho destacado), ele não oferece elementos para analisá-los.

É importante reiterar que, para Grice, a conversa é uma variedade da conduta racional. A conduta racional supõe que o participante conduz uma conversa de forma efetiva e cooperativa. Neste sentido, as implicaturas se baseiam na crença, compartilhada por falantes e ouvintes, de que as máximas não são, em geral, burladas durante a conversa; se esta burla ocorre, produz-se uma implicatura. A burla das máximas, portanto, na verdade mostra que estas são efetivamente operacionais. Por exemplo, uma sentença como "Você é o açúcar do meu café", que contém uma falsidade categorial, quebraria a máxima da qualidade. Esta quebra implica na interpretação pelo ouvinte que o propósito do falante não é definir o referente "você" nos termos da sentença, e sim remeter a outro significado.

Portanto, Grice considera o contexto fundamental à análise do significado. Ele entende contexto como "conhecimento de mundo"; no entanto, Grice não investigou em que consiste este conhecimento, limitando-se a apontar mecanismos dedutivos racionais, independentes da "situação de fala" específica. Estes fatores resultam na idealização da categoria "contexto". A teoria de Searle (1969/1983) também carece de uma análise mais aprofundada do contexto compreendido como "situação".

\section{A Pragmática Searleana}

Searle propõe o ato de fala como a unidade básica da comunicação. Uma questão básica sobre a linguagem consiste em explorar as relações entre o significado da sentença e o significado do falante, já que uma mesma emissão pode desempenhar diferentes atos de fala. Para identificar e distinguir tais atos, Searle estabelece cinco tipos de atos de fala diretos (assertivos, diretivos, compromissivos, expressivos e declarativos) e suas respectivas estruturas sintáticas. Nos atos de fala

3 Em outras palavras, se fornecemos mais ou menos informações do que é necessário, se dizemos algo que sabemos ou acreditamos estar errado, se dizemos algo que é irrelevante ao assunto da conversação, se falamos de modo obscuro, ambíguo ou confuso, isto se constitui em um comportamento não cooperativo. Toda a conversação pressupõe uma aceitação destas regras. A interpretação de quem escuta segue estas regras tacitamente. Uma destas regras é assumidamente violada, quando o interlocutor tem uma razão específica X para tal violação e porque sabe que quem o escuta é capaz de identificar X como a causa de sua violação. Grice (1957) define este tipo de inferência como "implicações conversacionais". A partir das afirmações acima se conclui que a violação de uma máxima é (e não pode deixar de sê-lo) dependente do contexto. 
diretos, portanto, não há tensão entre significado literal e não literal, sendo o primeiro um dos aspectos que define o significado comunicativo do enunciado.

O significado está atado a nossas noções de condições de verdade, implicação, imcompatibilidade, compreensão e uma grande quantidade de outras noções semânticas e mentais. Ora, a tese da relatividade do significado exposta por Searle é a tese de que essas conexões só se estabelecem relativamente a um sistema de coordenadas, constituído por suposições de base.

Para propósitos dessa discussão, é suficiente argumentar que a noção de significado literal absolutamente independente do contexto não tem aplicação geral a sentenças; de fato parece haver um grande número de sentenças para as quais poderíamos estender os tipos de argumentos em favor da dependência contextual da aplicabilidade do significado literal discutido anteriormente (SEARLE, 2000 , p. 188).

A tese proposta por Searle é que não há distinção precisa entre a competência lingüística do falante e seu conhecimento de mundo, assim o significado literal é dependente do contexto da mesma maneira que outras formas não conversacionais de intencionalidade são dependentes do contexto, e que não há maneira de eliminar a dependência, no caso do significado literal, que não rompa as conexões com outras formas de intencionalidade e, portanto, não elimine também a intencionalidade do significado literal ${ }^{4}$.

Mais complexos são os atos de fala indiretos, isto é, aqueles em que o significado da emissão do falante e o significado da sentença divergem. Um ato de fala indireto é, portanto, um ato ilocucionário realizado indiretamente através de outro. Por exemplo, no enunciado "você quer abrir a porta?", o propósito do falante não é requerer uma informação do ouvinte, e sim criar no mesmo um efeito que o leve a executar a ação em questão. Searle levanta quatro aspectos para a análise dos atos de fala indiretos:

Para ser mais específico, o aparato necessário para explicar a parte indireta dos atos de fala indiretos inclui uma teoria dos atos de fala, alguns princípios gerais de conversação cooperativa (alguns dos quais foram discutidos por Grice (1957)) e a informação factual prévia compartilhada pelo falante e pelo ouvinte, além da habilidade para o ouvinte fazer inferências (SEARLE, 1979, p. 50).

Searle compreende a habilidade para fazer inferências como uma estratégia que consiste em estabelecer, primeiramente, que o propósito ilocucionário diverge

4 Por exemplo, não há como eliminar a dependência contextual da sentença "o gato está sobre o capacho" sem romper as conexões entre essa sentença e a percepção de que o gato está sobre o capacho, e é dessas conexões que o significado da sentença literal depende. Ver John Searle (1979) Expression and Meaning. Cambridge University Press, p. 212. 
do literal e, em segundo lugar, qual é o propósito ilocucionário. Apesar de mencionar os elementos contextuais acima apontados, para Searle, nas obras referidas, o ouvinte toma a decisão que "o propósito ilocucionário primário diverge do literal" a partir do conceito de "intenção" (do falante).

\section{A Pragmática na Teoria dos Atos de Fala}

É importante observar que tanto Grice quanto Searle denunciam uma excessiva ênfase no conceito de "intencionalidade" 5 . As tradições teóricas de Grice e Searle constituem-se como modelos de inferências. Para Grice, o significado convencional figura no processo de cálculo das implicaturas; para Searle, a comunicação ocorre exatamente quando os indivíduos combinam o conhecimento de certos mecanismos lingüísticos com seu conhecimento das intenções e do contexto, identificando o ato de fala em questão. Estas tradições se apresentam, também, como modelos inferenciais, porque a dedução do "significado do falante" é central à teoria.

A pragmática, concebida como estudo da significação não-literal do locutor, faz parte da teoria dos atos de fala, porque a habilidade que têm os locutores de realizar e compreender os atos ilocucinários não-literais e as implicitações conversacionais, faz parte de sua competência para usar a linguagem e comunicar com ela. Num sentido importante, essa capacidade faz parte da competência lingüística do falante. Sem ela, os sujeitos falantes não poderiam utilizar plenamente a linguagem e se comunicar. Encontramos aqui a distinção entre frases e enunciados/proferimentos. Esta distinção ficará clara através de alguns exemplos: o mesmo enunciado pode ser feito com frases diferentes: posso enunciar o fato de Tony estar gordo com diferentes frases: "O Tony está mesmo gordo", "Que gordo está o Tony!", "Está gordo o Tony!"; por seu lado, a mesma frase pode servir para diferentes enunciados. Com a frase "Ana Laura é uma bela menina" tanto podemos fazer numa enunciação descritiva, como laudatória, ou até irônica. A mesma frase pode ser usada com sentidos completamente diferentes, dependendo isso do contexto em que é dita, ou seja, o uso que dela se faz. A gramaticalidade de uma frase significa, em termos pragmáticos, que a frase quando enunciada é compreensível a todos os ouvintes. Mas não basta uma frase ser compreensível, para ser um

5 "A intencionalidade é aquela propriedade de muitos estados e eventos mentais pela qual estes são dirigidos para, ou acerca de, objetos e estados de coisas no mundo. Se, por exemplo, eu tiver uma crença, deve ser uma crença de que determinada coisa é desse ou daquele modo; se tiver uma intenção deve ser uma intenção de fazer alguma coisa. De acordo com o princípio da intencionalidade as intenções devem ser sempre referentes a alguma coisa. Segundo esta explicação searleana, se um estado E é Intencional, deve haver uma resposta para perguntas como: A que se refere E? em que consiste E? O que é um E tal que?” (SEARLE, 1983, p. 2). 
enunciado. A capacidade que o interlocutor tem de compreender a asserção nãoliteral secundária neste caso ultrapassa, obviamente, sua capacidade de compreender a significação do enunciado utilizado no contexto dessa enunciação. A pragmática, concebida como a teoria da significação não-literal do locutor, deve responder às seguintes questões fundamentais:

1) como o locutor consegue fazer o interlocutor compreender que o que ele significa não é idêntico ao que ele diz, através do enunciado que ele usa no contexto de uma enunciação?

2) Uma vez que o interlocutor compreendeu isso, como ele consegue identificar o ato de discurso principal não-literal e as implicitações conversacionais da enunciação?

Grice (1989) nos oferece razões para acreditarmos que o locutor que pretende realizar um ato de discurso principal não literal ou implicar, conversacionalmente, alguma coisa, num contexto de enunciação, tem a intenção de se fazer compreender pelo interlocutor confiando que:

a) o interlocutor conhece a significação do enunciado que ele usa, e em particular, na sua capacidade de compreender as condições de sucesso e de satisfação dos atos de discurso;

b) o interlocutor que tem o mesmo conhecimento (que o locutor) de certos fatos do fundo conversacional sobre os quais ele pretende chamar a atenção do interlocutor; e

c) (o locutor) confia na capacidade do interlocutor de fazer inferências, baseado na hipótese de que o locutor respeita certas regras conversacionais, ao realizar o ato de discurso principal no contexto da enunciação.

Segundo esta análise, não é possível compreender o ato de discurso principal não-literal de uma enunciação sem ter identificado, antecipadamente, o ato de discurso literal, e sem ter compreendido que este ato literal não pode ser o ato de discurso principal no contexto dessa enunciação, se o locutor respeita as regras de conversação nesse contexto. Como conseqüência disto, a pragmática, concebida como a teoria da significação do locutor incorpora a semântica, concebida como a teoria da significação dos enunciados.

Para analisar, plenamente, a significação das enunciações não-literais, a pragmática precisa, além da semântica, recorrer às máximas conversacionais e aos fatos pertinentes do fundo conversacional do contexto da enunciação. As máximas conversacionais são diretivas, do gênero: "Diga a verdade!", "Seja sincero", e deixe que sua enunciação seja um ato ilocucinário bem sucedido e sem defeito!". Como Grice e Searle já demonstraram, não somente os locutores e os interlocutores respeitam tais máximas conversacionais, no uso e na compreensão das línguas naturais, mas é razoável para eles respeitarem essas máximas, se eles querem atingir seus objetivos lingüísticos, no curso das enunciações onde eles cooperam. Por 258 A Cor das Letras - UEFS, n. 8, 2007 
exemplo, quando um locutor pretende realizar antes de tudo um ato de discurso não-literal, ele explora tais máximas conversacionais no contexto de sua enunciação. Ele pretende então que o interlocutor reconheça que existem fatos no fundo conversacional que ele conhece e que o obriga a realizar não-literalmente alguma coisa além, se ele respeita essas máximas. Por exemplo, quando o locutor faz a pergunta "Você pode me passar o sal?", por ocasião de um jantar, ele pede indiretamente ao interlocutor para lhe passar o sal, este último compreende o ato de discurso indireto quando ele compreende que o locutor explora a máxima conversacional de quantidade: "deixe sua enunciação ser uma tentativa lingüística apropriada para atingir seus fins!" aparentemente, o locutor viola esta máxima no contexto de sua enunciação. Com efeito, sua pergunta literal não é o ato ilocucionário mais forte, que ele quer que seja satisfeito, pois o fundo conversacional é tal que ambos, locutor e interlocutor, sabem que o locutor precisa e antes de tudo, quer que o interlocutor lhe passe o sal. Porém, o locutor realmente respeita a máxima de quantidade, nesses contextos, se considerarmos o que ele pretende primeiramente.

De fato ao fazer sua questão literal, num contexto com um tal fundo conversacional, ele pretende muito mais do que ele diz, ele pretende fazer indiretamente um pedido não-literal mais forte, o qual é um meio lingüístico apropriado para atingir seus fins. Assim, em geral, no caso dos atos de discurso indiretos existe uma exploração da máxima de quantidade. $\mathrm{O}$ ato de discurso principal da enunciação é mais forte que o ato de discurso literal, por que ele tem condições de sucesso nãoliterais que são obviamente preenchidas no fundo conversacional, além das condições de sucesso e de satisfação dos atos de discurso literais ${ }^{6}$.

Tais fatos do fundo conversacional, de acordo com os exemplos citados anteriormente, não fazem parte do contexto da enunciação considerado na semântica. Não obstante tais fatos serão considerados na pragmática, porque eles ajudam a determinar a natureza dos atos ilocucionários não-literais e as implicações conversacionais; eles são, em geral, fatos que o locutor e o interlocutor conhecem mutuamente em virtudes da forma de vida que eles compartilham e das atividades nas quais eles estão engajados na sua comunidade social. Eles estão no fundo contextual da enunciação ${ }^{7}$.

É importante observar, com bastante minúcia, a integração da teoria dos atos de fala no interior da semiótica, pois existem áreas da teoria dos atos de discurso como, por exemplo, a teoria dos atos perlocucionários que não tem, ou quase não tem relevância semântica. Como Austin já observou, os atos perlocucionários

6 Ver o texto de Searle (1979) "Atos de fala indiretos", em Expression and Meaning, Cambridge University Press.

7 Ver o capítulo do Backgroud de John Searle (1983) em Intentionality, Cambridge University Press. 
são atos de discurso que os locutores realizam ocasionalmente (intencionalmente ou não) pela utilização dos enunciados. Assim, por exemplo, um locutor que diz (1) "seu perfume é barato", pode irritar intencionalmente ou embarassar perlocucionariamente o interlocutor, tal como um locutor que diz (2) "sua irmã é tão bonita quanto você?" pode ocasionalmente agradar ou divertir perlocucionariamente o interlocutor.

Ao contrário dos atos ilocucionários, os atos perlocucionários não são determinados pela significação dos enunciados. Por exemplo, faz parte da significação lingüística do enunciado interrogativo (2) perguntar se a irmã do interlocutor é tão bonita quanto ele, mas não faz parte da significação deste enunciado, que ao fazer esta pergunta o locutor possa ocasionalmente (intencionalmente ou não), agradar ou divertir, perlocucionariamente, o interlocutor. Os atos perlocucionários são realizados apenas ocasionalmente e podem sempre ser cancelados: nós podemos sempre imaginar um contexto de uso possível em português onde o locutor utilizaria o mesmo enunciado sem ter a menor intenção de realizar nenhum ato perlocucionário. Por esta razão, os atos perlocucionários não constituem unidades de significação semântica na linguagem.

\section{Algumas Considerações FinAIS...}

É importante observar que existem aspectos da significação dos enunciados como as implicações conversacionais ${ }^{8}$, que são logicamente independentes dos atos ilocucionários literais e que não podem ser estudadas plenamente na semântica dos atos de discurso. Por exemplo, os dois enunciados (3) "ele é gordo e não come muito" e (4) " ele é gordo mas ele não come muito" expressam as mesmas asserções nos mesmos contextos possíveis de enunciação, mas diferem em significação. Além disso, uma enunciação do primeiro enunciado serve para fazer uma asserção, enquanto que uma enunciação do segundo enunciado serve, além disso para expressar uma implicação conversacional (própria da significação da palavra "mas") que existe um contraste entre ser gordo e não comer muito.

Considerando os enunciados abaixo: (1) "José é trabalhador, contudo é pobre." (2) "João é carioca, portanto não é um homem sério.” No enunciado (1), está dito que José é trabalhador e que é pobre, mas não está dito que, sendo trabalhador, não devesse ser pobre. Isso está implicado através do significado convencional das palavras e, no caso, indicado através da conjunção "contudo". No exemplo (2), ocorre a mesma coisa. "João é carioca" e "João não é um homem sério" é o dito. Há, entretanto, uma implicatura convencional a partir da indicação feita pelo conetivo "portanto" de que o carioca não é serio e isso não foi, realmente, dito. Como se pode depreender dos exemplos dados, a implicatura convencional decorre da própria força significativa das palavras, sendo, por isso, intuída pelos interlocutores sem maiores dificuldades. 
A divisão entre significação literal e não literal, na análise semântica ainda não é clara, e requer uma decisão teórica em certos casos limites. Como os organismos vivos, as línguas naturais evoluem, e os modelos de significação não-literal do locutor, no fundo conversacional, têm a tendência a serem lexicalizadas depois de algum tempo, quando os fatos pertinentes do fundo conversacional são esquecidos. Assim, existem mudanças de significação e introduções de novas significações na história das línguas naturais, como é demonstrado pela existência das metáforas mortas.

Em certos casos limites, quando uma significação não literal do locutor é recorrente, por um longo período de tempo, nas conversações ordinárias, que os traços pertinentes ao fundo conversacional tornaram-se formas de vida correntes, podemos perguntar se uma nova significação literal não foi lexicalizada. Depois de tudo, devemos regularmente atualizar a significação das palavras nos dicionários de português como das outras línguas naturais.

Como foi colocado, a significação e o uso são logicamente relacionados na estrutura da linguagem, pois não existe um meio de analisar a significação lingüística de um enunciado, sem estudar os atos ilocucionários que podem ser realizados pelas enunciações nos contextos de uso apropriados. É possível perceber claramente que, em se tratando da linguagem em todos os seus aspectos constitutivos o pragmatismo compreende, além das dimensões sintática e semântica na análise do processo semiótico, uma dimensão contextual. Por que o signo, aqui entendido na dimensão dos atos de fala, não é independente da sua utilização. A dimensão pragmática é tal como as dimensões sintática e semântica da semiótica uma dimensão lógica. Em nossa análise, ficou claro que, de certo modo, a pragmática surge como um desenvolvimento imanente do processo semiótico. Com isto, quer-se dizer que tal como a análise dos signos linguísticos leva necessariamente à consideração dos valores semânticos como critério para definir as unidades sintáticas, assim também a análise do significado induz à consideração das condições e situações da sua utilização. A teoria dos atos de fala procura descrever o sistema fundamental de regras de uma competência enunciativa, isto é, não apenas de construção de frases, mas sim da sua aplicação correta em enunciados. O que está em causa, portanto, são as condições de enunciação.

\section{REFERÊNCIAS}

GRICE, Paul. Logic and Conversation. In: Id. Studies in the Way of Words. Cambridge: Harvard University Press, 1989.

GRICE, Paul. Meaning. Philosophical Review, Cornell University: Duke University Press, n. 67, p. 377-88, 1957.

MORRIS, Charles. Foundations of the Theory of Signs. Chicago: University of Chicago Press, 1959. 
SEARLE, J. R. Speech Acts. Cambridge: Cambridge University Press, 1969.

SEARLE, J. R. How Performatives Works. In: Linguistics and Philosophy, 12. Reeditado in Susumu Kubo \& Daniel Vanderveken. Essays in Speech Act Theory, Benjamins, 2000.

SEARLE, J. R. Intentionality. Cambridge: Cambridge University Press, 1983.

SEARLE, J. R. Expression and Meaning. Cambridge: Cambridge University Press, 1979. 